\title{
Barriers to Health Service Utilization Among Iranian Female Sex Workers: A Qualitative Study
}

\author{
Mehran Asadi-AliAbadi ${ }^{1,2}$, Jamileh Abolghasemi ${ }^{3}$, Shahnaz Rimaz ${ }^{1,4}$, Reza Majdzadeh ${ }^{5}$, Fereshteh Rostami-Maskopaee ${ }^{6}$, \\ Effat Merghati-Khoei \\ ${ }^{1}$ Department of Epidemiology, School of Public Health, Iran University of Medical Sciences, Tehran, Iran; ${ }^{2}$ Preventive Medicine and Public Health \\ Research Center, Iran University of Medical Sciences, Tehran, Iran; ${ }^{3}$ Department of Biostatistics, School of Public Health, Iran University of Medical \\ Sciences, Tehran, Iran; ${ }^{4}$ Radiation Biology Research Center, Iran University of Medical Sciences, Tehran, Iran; ${ }^{5}$ Community Based Participatory \\ Research Center and Knowledge Utilization Research Center, Tehran University of Medical Sciences, Tehran, Iran; ${ }^{6}$ Department of Public Health, \\ School of Public Health, Mazandaran University of Medical Sciences, Sari, Iran; ${ }^{7}$ Iranian Center of Addiction Studies (INCAS), Tehran University of \\ Medical Sciences, Tehran, Iran
}

Objectives: In most countries around the world, sex work is an illegal activity. Female sex workers (FSWs) in Iran hide their identities, and they are known to be a hard-to-reach population. Despite free access to HIV testing, fewer than half of FSWs receive HIV testing. The purpose of this study was to characterize the reasons for which FSWs do not seek testing at drop-in centers (DICs) and voluntary counseling and testing (VCT) centers in Iran.

Methods: A qualitative study was conducted in 2016. The participants were 24 FSWs who received services at VCT centers and DICs for vulnerable females in the north of Iran and 9 males who were the clients of FSWs. In this study, we made use of purposive sampling and carried out a thematic analysis.

Results: We found 4 major and 6 minor themes. The major themes were: fear of being infected (with HIV), stigma, indifference, and knowledge.

Conclusions: Despite the significant efforts made by the government of Iran to establish and expand DICs for vulnerable females, the number of FSWs receiving services at these centers has not been very considerable. Consequently, by introducing and implementing training programs for peer groups, it may be possible to take steps toward establishing strategic programs for the control and prevention of HIV/AIDS.

Key words: Sex workers, Human immunodeficiency virus, Health services, Iran

Received: October 30, 2017 Accepted: January 6, 2018

Corresponding author: Shahnaz Rimaz, PhD

Department of Epidemiology, School of Public Health, Iran University of Medical Sciences, Shahid Hemmat Highway, Tehran 1449614535, Iran

\section{E-mail: srimaz2000@yahoo.com}

This is an Open Access article distributed under the terms of the Creative Commons Attribution Non-Commercial License (http://creativecommons.org/licenses/bync/4.0/) which permits unrestricted non-commercial use, distribution, and reproduction in any medium, provided the original work is properly cited.

\section{INTRODUCTION}

The manner in which sex work is carried out and its legal status are different in various regions. In socioculturally conservative countries, as well as in Islamic countries in the Middle East, female sex workers (FSWs) are considered to be "social evils" and "norm-breakers." Therefore, they are often excluded from society, which puts them at risk of social harm and endangers their social welfare, access to health care services, and reproductive health rights. 
FSWs are known to be a key population that plays an important role in the dynamics of HIV transmission, and the Joint United Nations Programme on HIV/AIDS reported the worldwide HIV prevalence among this population to be approximately $11.8 \%$ in 2015 [1]. Due to the types and the number of FSWs' sexual partners or clients (i.e., their sexual network), they can contribute to an increased rate of HIV transmission. Nonetheless, their clients, as the bridge population that transmits the infection to other people in society, play the most important role [2,3]. It is estimated that approximately 80000 FSWs live in Iran, of whom $4.5 \%$ are HIV-positive [4]. However, this information is derived from estimates obtained from drop-in centers (DICs) and voluntary counseling and testing (VCT) centers, which means that this number is likely to be an underestimate [4].

Currently, the AIDS epidemic is concentrated in certain subgroups of the population in Iran. More than 5\% of the highrisk population and less than $1 \%$ of the general population is affected by this infection [2]. Meanwhile, according to the latest (2016) report of the Ministry of Health and Medical Education of Iran, approximately 32000 HIV-positive individuals have been identified [5]. However, in a study published in 2011 , researchers estimated that this number would increase to 106000 cases by the end of 2014 [4]. Taken together, these findings indicate that most HIV-positive individuals are not aware of their disease status, and therefore act as hidden or potential sources of HIV transmission. The third wave of HIV transmission is reported to be moving through unprotected sexual intercourse [4], and the Ministry of Health and Medical Education of Iran has reported that $42 \%$ of cases of HIV transmission in the beginning of 2016 took place through sexual intercourse [6].

A national monitoring and evaluation program conducted in 2009 throughout 10 provinces in Iran showed that FSWs who received HIV testing and counseling services at VCT centers and DICs in 2007 and 2008 had HIV positivity rates of 5 and 7\%, respectively [7]. In 2007 and 2008, 14.0 and $17.5 \%$ of FSWs, respectively, received counseling at DICs and VCT centers [8]. Moreover, despite free access to HIV testing for FSWs, fewer than half of them received HIV testing in 2010 [9]. In a study of FSWs living in Tehran in 2007, 59.3\% of them stated that they know where to go to get an HIV test [10]. Studies have found that the majority of FSWs visit private health centers to receive health and treatment services. However, these centers do not provide regular reports of the services they provide [11-13]. One of the most important reasons why FSWs do not visit DICs and VCT centers for health and treatment services is the discrimination and stigma associated with HIV infection. This finding has been reported in the majority of the studies carried out to investigate this issue [9,14-16]. Fear of identification and punishment for engaging in sex work, the stigma conveyed by the service providers, distance to the centers, and fear of HIV testing have been reported as major obstacles in many studies [9].

In most countries around the world, sex work is an illegal activity. Iran is a country in which sex work is considered to be a crime with severe punishments. However, although sex work is associated with important public health issues, FSWs in Iran hide their identity, and they are known to be a hard-to-reach population [9]. Initially, due to the cultural limitations in providing health services to FSWs, a goal of providing counseling and voluntary testing to $17 \%$ of this population seemed appropriate. However, because of the increased prevalence of HIV infection in FSWs and the risk of a concentrated epidemic emerging among them, which could cause HIV to spread among the general population, broader planning to increase coverage for preventive and diagnostic services for these groups is necessary [8].

In order to successfully implement preventive and surveillance programs for HIV/AIDS, it is necessary to have access to high-risk groups to ensure the optimal efficacy of the programs. Therefore, peer groups can be of great significance for the success of such programs. The purpose of this study was to characterize the reasons for which FSWs do not seek counseling and testing services at DICs and VCT centers in Iran through qualitative methods.

\section{METHODS}

A qualitative study was conducted in 2016, and the participants were 24 FSWs who received services at VCT centers and DICs for vulnerable females in the north of Iran and 9 male clients of FSWs. Forty-nine females who received services at these centers were initially invited to participate in the study, and 24 of those females met the inclusion criteria. Twenty-one male clients of FSWs were initially invited, but only 9 met the inclusion criteria. The inclusion criteria for the FSWs were as follows: being a female 18 years or older, having sex work experience or being the madam (i.e., manager) of other FSWs for at least 1 year, being the acquaintance or friend of 5-7 FSWs 
who had not received services at these centers; and completing the informed consent form to participate in the study. The inclusion criteria for male clients of FSWs were as follows: being a male 18 years or older; having had at least 1 sexual contact with FSWs per month during the last year; being familiar with 5-7 FSWs who had not received services at these centers, and completing the informed consent form to participate in the study. Before starting this study, all participants were informed about the topic and purpose of the study. In addition, they were informed that they were free to participate in the study or to discontinue participation, and written informed consent was provided by each participant.

First, the interview guide was prepared and provided to the interviewees. Then, semi-structured in-depth interviews were conducted with the participants. They were individually interviewed in a private room. Participants were asked for their opinions about the factors that prevented FSWs from visiting VCT centers and DICs for services. Two interviewers (1 male and 1 female) who were trained and experienced in this context (VCT center and DIC staff) conducted the interviews, which were recorded. Data were gathered through the recordings of the interviews. Then, notes taken about the interviews and the data were coded by 2 experts based on the purposes of the study, and the themes were identified. In each coding session, key and significant expressions in each text were identified in relation with the topic and the individual. Coding was conducted in 3 stages:

1) free coding (first stage), 2) axial coding (second stage), 3) selective coding (third stage)

In this study, we used purposive sampling. After 33 interviews ( 24 females and 9 males), we were theoretically saturated, and no additional information emerged after the 24th interview. The interviews were conducted in a way that was suitable for sensitive issues. In-depth interviews conducted by the first author lasted between 1 and 4 hours, and several audit were held prior to the interview to build rapport with the interviewee. A female interviewer conducted the interviews with the FSWs, and a male interviewer interviewed the male clients. The data were analyzed using content analysis. In this type of qualitative analysis, the data are minimized and structured in an orderly manner. In addition, repetition, occurrence, meaning, and the relationships between certain words in the transcripts and concepts were determined. In this stage, the content of the message that needed to be analyzed was defined. Moreover, attempts were made to recognize the units of content analysis. The interviews were read several times, and then the participants' ideas and experiences with regard to barriers preventing FSWs from receiving services at DICs and VCT centers were extracted and saved as text. After that, the coding stage was conducted.

Factors such as fear, stigma, indifference, and lack of knowledge are very sensitive items in Iran, which prevents FSWs from visiting these centers for counseling and testing. It is essential to consider the importance of these major themes and their tangibility, especially in tourist areas in tourist areas in northern Iran along the Caspian Sea.

Additionally, sub-themes were extracted from the same questions as the main themes.

\section{Ethical Considerations}

This study received an ethical and project code (25463) from the Vice-Chancellery of Research of Iran University of Medical Sciences. All participants provided written consent to participate in the study and all interviews were conducted anonymously.

\section{RESULTS}

\section{Demographic Features}

The female participants' age range was from 25 to 39 years, and the male participants' age range was from 23 to 35 years. The females's age of first sexual contact was from 12 to 34 , and that of the males was from 16 to 21 years. The average age of first sexual contact for the females and males was 20.5 and 18.0 , respectively. The females's average age at beginning sex work was 22.5 years (range, 12-34). A minority of the females (23.8\%) were not local; the rest, as well as the male clients, were all local. Of the FSWs, $52.4 \%$ were divorced, $19.0 \%$ were married, $19.0 \%$ were single, and $9.6 \%$ were in a sigheh (temporary marriage) relationship. Of the males, $55.6 \%$ were single, $22.2 \%$ were separated from their family, $11.1 \%$ were divorced, and $11.1 \%$ were married. In $81.0 \%$ of cases, the place for having sexual intercourse was determined by the clients, while in the remaining cases, it was determined by the FSWs. The females methods for finding clients varied, including through cell phones and the Internet (38.0\%), introductions from friends and other clients (14.3\%), on the streets (19.0\%), and other ways (28.7\%). Of the FSWs with marriage experience, $41.2 \%$ had experienced 2 or more marriages. 


\section{Qualitative Findings}

A thematic analysis was conducted of the $24 \mathrm{FSWs}$ and $9 \mathrm{cli}-$ ents, and the results are presented in Table 1 by main and minor themes. The interpretation of the thematic analysis was as follows:

\section{Fear of being infected (HIV)}

One of the main reasons why FSWs were not willing to receive counseling and testing at DICs and VCT centers, which provide health and treatment services, was that they feared being officially diagnosed with an HIV infection; therefore, for receiving services, they preferred visiting other centers (private) that provide anonymous testing. Regarding this issue, one of the participants stated:

I fear being infected with the disease. If I find out that I am infected, I may get depressed or lose my hopes for living, and so on.

Another participant stated:

I have a friend who has a lot of sexual relations and I know her circumstances. I asked her to come to these places and have some tests done. Their services are free, and you don't need to pay anything. But she always says, "Drop it; I'm afraid, I fear being infected."

\section{Stigma (low quality of drop-in centers and voluntary counseling and testing services)}

During the interviews, most of the participants mentioned confidentiality and the supportive services offered by the centers as major reasons for not visiting them for testing and counseling. In this regard, one of the participants stated:

The main reason why people do not visit these centers is that they cannot trust them. They think that these centers will reveal their secrets or that their names will be reported somewhere.

Another issue identified by some participants was the inappropriate location of these centers, which can attach stigma to the people visiting them for services. Due to this stigma, most HIV-positive individuals postpone visiting these centers for surveillance or treatment, and they do not follow their surveillance programs correctly.

Another participant stated:

Going to these centers is often very difficult for us. This center is an example, because in front of the entrance, there is a taxi stand. The drivers look at whoever comes in, and they ask: What is this place? Why are these females visiting this center? What is their problem? Who are they? What's wrong with them? And so many other questions!

\section{Indifference}

Many drug-addicted females, due to their addiction, do not use condoms and do whatever their clients desire. Most such FSWs described experiencing physical injuries, such as sexual violence and other types of violence. They stated that when the clients became aware of the FSWs' addictions, they misuse them and do not care about whether the FSWs ask to use a condom. Moreover, drug-addicted FSWs stated that using a condom was not very important for them and that obtaining drugs was the only significant issue that they thought about at the time [17].

Most of the participants in the present study confirmed these issues. One stated:

These people do not care about their health. That is why they do not set aside time to come here and receive the education needed to change their lifestyle and behaviors.

\section{Knowledge}

Some of the participants stated that most people were not aware of these centers or they did not know where the centers were. In this regard, a participant said:

You know, some of these people do not know anything about

Table 1. Thematic analysis of barriers to health service utilization by female sex workers according to major and minor themes

\begin{tabular}{|c|c|c|c|}
\hline Topic & Major themes & Respondents (n) & Minor themes \\
\hline \multirow{8}{*}{$\begin{array}{l}\text { Reasons for not } \\
\text { receiving } \\
\text { services at } \\
\text { drop-in centers } \\
\text { and voluntary } \\
\text { counseling and } \\
\text { testing centers } \\
\text { (governmental) }\end{array}$} & \multirow[t]{2}{*}{ Fear } & Female (20) & \multirow{2}{*}{$\begin{array}{l}\text { Fear of the emotional aftermath of HIV infection and fear of the disease of } \\
\text { AIDS }\end{array}$} \\
\hline & & Male (4) & \\
\hline & \multirow[t]{2}{*}{ Stigma } & Female (22) & $\begin{array}{l}\text { Not trusting these centers to keep their information confidential or to provide } \\
\text { support for them }\end{array}$ \\
\hline & & Male (7) & Inappropriate location of the centers \\
\hline & \multirow[t]{2}{*}{ Indifference } & Female (17) & Addiction, indifference, and nonchalance \\
\hline & & Male (6) & \\
\hline & \multirow[t]{2}{*}{ Knowledge } & Female (15) & Lack of awareness of these centers \\
\hline & & Male (5) & Lack of knowledge about HIV and its transmission (lack of awareness) \\
\hline
\end{tabular}


these centers or the places that provide various services. Maybe there are not enough advertisements. People don't know about these centers. You know, they don't know that they can come here to receive treatment, receive counseling, talk about their problems, or at least be trained for a job or profession.

One of the greatest challenges for various groups throughout society, especially high-risk groups, is insufficient knowledge about HIV/AIDS and its transmission routes. In this regard, another participant stated:

These people are not aware of the risks related to their activities. For example, they don't know anything about the consequences of having sexual contacts with various people without using a condom.

\section{DISCUSSION}

In this study, 4 main themes were identified: fear, stigma, indifference, and knowledge.

We found that a major reason why FSWs do not visit DICS and VCT centers to receive services is their fear of being infected with HIV/AIDS, and their fears of its mental and emotional aftermath.

Due to the fear of becoming an outcast and the other social consequences of HIV infection, these groups reject the possibility of having such a disease and they do not seek out voluntary HIV testing, which is known to be a significant preventive measure that can be taken against HIV and its spread throughout society $[18,19]$. The fear of being identified as an infected person is prevalent in most countries. Thus, FSWs' fear of being infected is a reason why they do not visit DICs for testing [13, 20,21].

Additionally, the participants expressed concerns about stigma and discrimination in the form of a lack of confidence in these centers, particularly regarding confidentiality and support services. Similarly, other studies have found stigma, discrimination, and lack of confidentiality to be barriers preventing FSWs from visiting such centers [22-24]. In addition to HIV stigma and discrimination, which create barriers for patients and high-risk individuals, the possibility that access to and utilization of HIV prevention services may be subsequently disrupted can lead to severe psychological injury in these people. Studies have indicated that HIV-infected individuals, as well as those suspected to have HIV, who have been stigmatized or discriminated against can lose their self-esteem and suffer from depression and hopelessness $[25,26]$. More- over, stigma and discrimination can indirectly lead to the social isolation of people with HIV or suspected to have HIV.

It is a reality that HIV-positive individuals can be isolated from other people as part of various HIV control measures [27]. Stigma and discrimination cause HIV-positive people to be viewed as a problem, not as the solution for this epidemic. Moreover, by not allowing people with HIV to participate in programming for AIDS control measures, we lose opportunities for managing AIDS prevention and the AIDS epidemic itself $[28,29]$.

Participants also identified a lack of awareness of the existence of these centers, as well as of the routes of HIV transmission. Similarly, in some other studies conducted in Iran and certain other countries, one of the main reasons for which people did not visit these centers for services was reported to be their lack of knowledge about the disease or their unawareness of centers that provide HIV-related services [30-32]. Moreover, according to the most recent population-based study of Iranian youths' knowledge, attitudes, and practices, more than $60 \%$ of the participants did not have enough knowledge about AIDS, and they believed that no supportive measures were provided by state centers [33]. Nonetheless, increasing awareness of HIV/AIDS can be a powerful tool for improving positive attitudes throughout society and facilitating the adoption of methods to prevent HIV transmission. Obtaining a clear understanding of the knowledge, attitudes, and practices of each society can make a highly significant contribution for strategic programming aimed at controlling and preventing HIV infections [34].

One of the most important limitations of this study is the lack of access to FSWs who did not visit these centers. Due to the severe legal and extra-legal consequences of sex work in Iran, as it is both a crime and a socially stigmatized behavior, this population is difficult to access. Moreover, FSWs may not provide accurate information to health service providers. For these reasons, in this study, people who were close to such FSWs were selected for interviews.

Despite the significant efforts made by the Iranian government to establish and expand VCT centers and DICs for vulnerable females, the number of FSWs receiving services at these centers has not been very considerable. This issue is one of the greatest limitations in implementing strategic programs for the prevention and control of HIV infection [8].

For the reasons we have discussed, the most hidden and hard-to-reach populations in society, which can be exposed to 
sexually transmitted diseases, especially HIV/AIDS, may not be easily accessible or visible. Based on the results of the present study, factors that prevent FSWs from accessing HIV counseling and testing services should be identified and minimized. Therefore, various methods, such as increasing knowledge and providing the appropriate social context by gaining access to high-risk groups, can be very effective measures in practice. Consequently, by introducing and implementing training programs for peer groups in Iran and other countries facing similar challenges, it may be possible to take steps towards establishing strategic programs for the control and prevention of HIV/AIDS.

\section{ACKNOWLEDGEMENTS}

We would like to express our special thanks to the ViceChancellor of Health of the Mazandaran University of Medical Sciences and the Vice-Chancellor of Research of Iran University of Medical Sciences, who helped us carry out this study. This study is part of an approved project (code: 25463) at Iran University of Medical Sciences.

\section{CONFLICT OF INTEREST}

The authors have no conflicts of interest associated with the material presented in this paper.

\section{ORCID}

Mehran Asadi-Aliabadi https://orcid.org/0000-0003-15825489

Jamileh Abolghasemi https://orcid.org/0000-0003-38982217

Shahnaz Rimaz https://orcid.org/0000-0001-6869-5847

Reza Majdzadeh https://orcid.org/0000-0001-8429-5261

Fereshteh Rostami-Maskopaee https://orcid.org/0000-00019856-6026

\section{REFERENCES}

1. Joint United Nations Programme on HIV/AIDS (UNAIDS). Global report: UNAIDS report on the global AIDS epidemic 2013 [cited 2018 Mar 2]. Available from: http://files.unaids. org/en/media/unaids/contentassets/documents/epidemiology/2013/gr2013/UNAIDS_Global_Report_2013_en.pdf.
2. Shokoohi M, Karamouzian M, Khajekazemi R, Osooli M, Sharifi $\mathrm{H}$, Haghdoost AA, et al. Correlates of HIV testing among female sex workers in Iran: findings of a national bio-behavioural surveillance survey. PLoS One 2016;11(1):e0147587.

3. Merghati-Khoei E, Rimaz S, Korte JE, Back SE, Brady KT, Abad M, et al. Intimate partner violence and risky sexual behaviors among Iranian women with substance use disorders. Med J Islam Repub Iran 2015;29:174.

4. Haghdoost AA, Mostafavi E, Mirzazadeh A, Navadeh S, Feizzadeh $\mathrm{A}$, Fahimfar $\mathrm{N}$, et al. Modelling of HIV/AIDS in Iran up to 2014. J AIDS HIV Res 2011;3(12):231-239.

5. Ministry of Health and Medical Education. Islamic Republic of Iran AIDS progress report; 2015 [cited 2018 Mar 3]. Available from: http://www.unaids.org/sites/default/files/country/documents/IRN_narrative_report_2015.pdf.

6. UNAIDS. Islamic Republic of Iran: 2016 [cited 2018 Mar 26]. Available from: http://www.unaids.org/en/regionscountries/ countries/islamicrepublicofiran.

7. Asadi-Ali Abadi M, Abolghasemi J, Rimaz S, Majdzadeh R, Shokoohi M, Rostami-Maskopaee F, et al. High-risk behaviors among regular and casual female sex workers in Iran: a report from Western Asia. Iran J Psychiatry Behav Sci 2018. doi: https:// doi.org/10.5812/ijpbs.9744.

8. Shokoohi M, Noori A, Karamouzian M, Sharifi H, Khajehkazemi $\mathrm{R}$, Fahimfar N, et al. Remaining gap in HIV testing uptake among female sex workers in Iran. AIDS Behav 2017;21(8): 2401-2411.

9. Karamouzian M, Akbari M, Haghdoost AA, Setayesh H, Zolala F. "I am dead to them": HIV-related stigma experienced by people living with HIV in Kerman, Iran. J Assoc Nurses AIDS Care 2015;26(1):46-56.

10. Ghahfarokhi SM, Forouzan AS, Roshanfekr P, Mohammadi MA, Dejman M, Vameghi M, et al. HIV/AIDS related knowledge and attitude among female sex workers in Tehran/Iran. Retrovirology 2010;7(Suppl 1):P130.

11. Ebrahim M, Nawab S. HIV/AIDS prevention: an Islamic perspective experience from South Africa. Tehran: Federation of Islamic Medical Associations; 2007, p. 91-100.

12. Javidan M, Dastmalchian A. Culture and leadership in Iran: the land of individual achievers, strong family ties, and powerful elite. Acad Manag Perspect 203;17(4):127-142.

13. Teklehaimanot HD, Teklehaimanot A, Yohannes M, Biratu D. Factors influencing the uptake of voluntary HIV counseling and testing in rural Ethiopia: a cross sectional study. BMC Public Health 2016;16:239. 
14. Carr RL, Gramling LF. Stigma: a health barrier for women with HIV/AIDS. J Assoc Nurses AIDS Care 2004;15(5):30-39.

15. Duffy L. Suffering, shame, and silence: the stigma of HIV/AIDS. J Assoc Nurses AIDS Care 2005;16(1):13-20.

16. Genberg BL, Hlavka Z, Konda KA, Maman S, Chariyalertsak S, Chingono A, et al. A comparison of HIV/AIDS-related stigma in four countries: negative attitudes and perceived acts of discrimination towards people living with HIV/AIDS. Soc Sci Med 2009;68(12):2279-2287.

17. Khah Malery Langeroudi Z, Delbarpour Ahmadi S, Esmaeili M. Barriers of condom use among female sex workers in Tehran, a qualitative study. J Sch Public Health Inst Public Health Res 2014;12(2):23-34 (Persian).

18. Bouton RA, Gallaher PE, Garlinghouse PA, Leal T, Rosenstein LD, Young RK. Scales for measuring fear of AIDS and homophobia. J Pers Assess 1987;51(4):606-614.

19. Bowen P, Govender R, Edwards P, Cattell K. An explanatory model of attitudinal fear of HIV/AIDS testing in the construction industry. Eng Constr Archit Manag 2016;23(1):92-112.

20. Meiberg $A E$, Bos AE, Onya HE, Schaalma HP. Fear of stigmatization as barrier to voluntary HIV counselling and testing in South Africa. East Afr J Public Health 2008;5(2):49-54.

21. Wang Y, Li B, Zheng J, Sengupta S, Emrick CB, Cohen MS, et al. Factors related to female sex workers' willingness to utilize VCT service: a qualitative study in Jinan city, northern China. AIDS Behav 2009;13(5):866-872.

22. Kawichai S, Celentano DD, Chaifongsri R, Nelson KE, Srithanaviboonchai K, Natpratan C, et al. Profiles of HIV voluntary counseling and testing of clients at a district hospital, Chiang Mai Province, northern Thailand, from 1995 to 1999. J Acquir Immune Defic Syndr 2002;30(5):493-502.

23. Kawichai S, Celentano DD, Vongchak T, Beyrer C, Suriyanon V, Razak $\mathrm{MH}$, et al. HIV voluntary counseling and testing and HIV incidence in male injecting drug users in northern Thailand: evidence of an urgent need for HIV prevention. J Acquir Immune Defic Syndr 2006;41(2):186-193.
24. Thepthien B, Srivanichakorn S. Barriers to VCT for vulnerable and non-vulnerable population at risk of HIV. J AIDS Clin Res 2016;7(3):552.

25. Brown MJ, Serovich JM, Kimberly JA, Hu J. Psychological reactance and HIV-related stigma among women living with HIV. AIDS Care 2016;28(6):745-749.

26. Turan B, Smith W, Cohen MH, Wilson TE, Adimora AA. Depression and social isolation mediate effect of HIV stigma on women's ART adherence; 2016 [cited 2018 Mar 4]. Available from: http://www.natap.org/2016/CROI/croi_37.htm.

27. Rintamaki LS, Davis TC, Skripkauskas S, Bennett CL, Wolf MS. Social stigma concerns and HIV medication adherence. AIDS Patient Care STDS 2006;20(5):359-368.

28. Burkholder GJ, Harlow LL, Washkwich JL. Social stigma, HIV/ AIDS knowledge, and sexual risk. J Appl Biobehav Res 1999; 4(1):27-44.

29. Pryor JB, Bos AE. Social psychological perspectives on stigma: advances in theory and research. London: Routledge; 2016, p. $1-3$.

30. Abachi A, Behravan $\mathrm{H}$. The analysis of stigma impact on quality of life in patients with HIV/AIDS: a phenomenological study. J Qual Res Health Sci 2013;2(2):158-172 (Persian).

31. Bucardo J, Semple SJ, Fraga-Vallejo M, Davila W, Patterson TL. A qualitative exploration of female sex work in Tijuana, Mexico. Arch Sex Behav 2004;33(4):343-351.

32. Najarkolaei FR, Niknami S, Shokravi FA, Ahmadi F. Perception and behaviors of HIV/AIDS patients: a qualitative study. J Kermanshah Univ Med Sci 2009;13(3): 220-234 (Persian).

33. Shokoohi M, Karamouzian M, Mirzazadeh A, Haghdoost A, Rafierad AA, Sedaghat $A$, et al. HIV knowledge, attitudes, and practices of young people in Iran: findings of a national population-based survey in 2013. PLoS One 2016;11(9):e0161849.

34. Fraim NL. Knowledge levels and misconceptions about HIV/ AIDS: what do university students in Turkey really know. Int J Humanit Soc Sci 2012;2(2):50-58. 